\title{
Shorter Periconception Maternal Telomere Length and the Risk of Congenital Cardiac Outflow Defects in the Offspring: a case control study
}

\author{
Damiat Aoulad Fares ${ }^{1}$, Rosalieke Wiegel ${ }^{1}$, Alex Eggink ${ }^{2}$, Sten Willemsen ${ }^{1}$, Joyce Van \\ Meurs $^{1}$, and Regine Steegers-Theunissen ${ }^{3}$ \\ ${ }^{1}$ Erasmus Medical Center \\ ${ }^{2}$ Erasmus MC \\ ${ }^{3}$ Erasmus MC, University Medical Centre
}

April 8, 2021

\begin{abstract}
Objective: Congenital cardiac outflow defects (COD) are the largest group of congenital heart defects, with ventricular septal defect (VSD) as the most prevalent phenotype. Increased maternal age, excessive oxidative stress and inflammation are involved in the pathophysiology and enhance telomere length (TL) shortening. We aim to study the association between periconception maternal TL, as future predictive biomarker, and the risk of having a child with COD. Design: HAVEN-study, a multicenter case-control triad study conducted in the Netherlands. Setting and population: 306 case mothers of a child with COD and 424 control mothers of a child without a congenital malformation were selected. Methods: TL was estimated, on DNA from venous blood samples, by qPCR. Multivariable logistic regression was used to compute crude and adjusted odds ratios (OR) per standard deviation (SD) decrease between maternal T/S ratio and COD and VSD risk. Main outcome measures: The risk of COD in offspring. Results: A significant association was shown between maternal TL shortening (per standard deviation) and a $29 \%$ increased risk of VSD in offspring (OR 1.29(95\% CI 1.04-1.61), P=0,02), which remained significant after additional adjustment for maternal age (adjOR 1.25(95\% CI 1.01-1.55), $\mathrm{P}=0,04)$. No association between maternal TL and the risk of overall COD in offspring was observed. Conclusion: Shortening of maternal TL, due to maternal conditions including age, is associated with an approximately 1.3-fold increased risk, per SD in TL-shortening, of VSD in the offspring. These findings need further confirmation in other studies on the predictive value of maternal TL.
\end{abstract}

\section{Shorter periconception Maternal Telomere Length and the Risk of Congenital Cardiac Outflow Defects in the Offspring: a case control study}

Damiat Aoulad Fares MD, Rosalieke E. Wiegel ${ }^{1}$ Ms, Alex J. Eggink ${ }^{1}$ MD, PhD, Sten P. Willemsen ${ }^{1,3}$ PhD, Joyce B.J. van Meurs ${ }^{2} \mathrm{PhD}$, Régine P. M. Steegers-Theunissen ${ }^{1} \mathrm{MD}, \mathrm{PhD}$

${ }^{1}$ Department of Obstetrics and Gynaecology, Erasmus MC, University Medical Centre, Rotterdam, the Netherlands. ${ }^{2}$ Department of Internal Medicine, Erasmus MC, University Medical Centre, Rotterdam, the Netherlands. ${ }^{3}$ Department of Biostatistics, Erasmus MC, University Medical Centre, Rotterdam, The Netherlands.

\section{Correspondence:}

Prof. dr. Régine Steegers-Theunissen

Department of Obstetrics and Gynaecology 
Erasmus MC, University Medical Center Rotterdam

P.O. Box 2040

3000 CA Rotterdam

Netherlands Email address: r.steegers@erasmusmc.nl

Shortened running title Telomere length and the risk of congenital cardiac outflow defects.

Word count

Abstract word count: 250 Main text: 2970

\begin{abstract}
Objective : Congenital cardiac outflow defects (COD) are the largest group of congenital heart defects, with ventricular septal defect (VSD) as the most prevalent phenotype. Increased maternal age, excessive oxidative stress and inflammation are involved in the pathophysiology and enhance telomere length (TL) shortening. We aim to study the association between periconception maternal TL, as future predictive biomarker, and the risk of having a child with COD.Design : HAVEN-study, a multicenter case-control triad study conducted in the Netherlands.Setting and population306 case mothers of a child with COD and 424 control mothers of a child without a congenital malformation were selected.
\end{abstract}

MethodsTL was estimated, on DNA from venous blood samples, by qPCR. Multivariable logistic regression was used to compute crude and adjusted odds ratios (OR) per standard deviation (SD) decrease between maternal $\mathrm{T} / \mathrm{S}$ ratio and $\mathrm{COD}$ and VSD risk.

\title{
Main outcome measures
}

The risk of COD in offspring

Results : A significant association was shown between maternal TL shortening (per standard deviation) and a $29 \%$ increased risk of VSD in offspring (OR 1.29(95\% CI 1.04-1.61), P=0,02), which remained significant after additional adjustment for maternal age (adjOR 1.25(95\% CI 1.01-1.55), $\mathrm{P}=0,04)$. No association between maternal TL and the risk of overall COD in offspring was observed.ConclusionShortening of maternal TL, due to maternal conditions including age, is associated with an approximately 1.3 -fold increased risk, per SD in TL-shortening, of VSD in the offspring. These findings need further confirmation in other studies on the predictive value of maternal TL.

Keywords

Maternal age, biomarker, congenital heart defects, oxidative stress, life course

Tweetable abstract Shorter maternal telomere length is associated with an almost $30 \%$ higher risk of offspring with a ventricular septum defect.

\section{Introduction}

Congenital heart defects (CHD) are among the most common congenital malformations in newborns with approximately 1 million children born each year worldwide. Although the mortality of CHD has decreased in the past decade(1), the quality of life of these patients is often compromised due to severe physical and psychological problems.(2) Several studies have shown a multifactorial origin of birth defects like CHD, where interactions between genetic predispositions and environmental exposures in early pregnancy are strongly involved in the pathogenesis.(3) The most common CHD are cardiac outflow defects (COD), with ventricular septal defect (VSD) as the most prevalent phenotype, accounting for approximately $35 \%$ of CHD.(1) COD share the same multifactorial origin and pathogenesis as neural tube defects where derangements in neural crest cells due to induced excessive oxidative stress and inflammation, are involved in the pathophysiology. 
The extracardiac contribution of neural crest cells together with the secondary heart field, both located in the pharynx, play an essential role in the septation process of the outflow tracts of the cardiac ventricle. $(4$, $5)$

Maternal hyperhomocysteinemia is a risk factor for the development of neural crest related anomalies in offspring, like spina bifida, cleft lip and/or palate and congenital outflow defects in offspring.(6, 7) Hyperhomocysteinemia disturbs apoptosis and myocardialization of the cardiac outflow tract, by affecting the cardiac neural crest cells.(8) Maternal health conditions, such as maternal age, obesity, tobacco and alcohol use, poor nutrition and lifestyle enhances oxidative stress and inflammation and are identified as risk factors for COD.(9) Telomeres are nucleoprotein structures that cap the end of chromosomes and thereby protect against unwanted recombination and degradation.(10) In humans, TL shortens in somatic cells with advancing age due to the increased number of cellular divisions. Excessive TL shortening is an index of senescence, causes genomic instability and is associated with a higher risk of age-related diseases. Recent findings showed that newborn TL determines the adult TL(11). It has been suggested that TL is a long term biomarker of chronic oxidative stress compared to hyperhomocysteinemia as short term biomarker. $(12,13)$ Primary prevention of COD in offspring might be possible when we have more insight into the role of TL as a biomarker in the pathogenesis to be used as future predictor of COD, and the associations with maternal health conditions. Therefore, as a first step we aim to study the association between periconception maternal TL and the risk of having a child with a neural-crest related COD.

Materials and Methods Study populationData and blood samples were used from the HAVEN-study (Acronym for Heart Defects, Vascular Status, Genetic Factors and Nutrition), a multicenter case control triad study on COD, conducted at the Department of Obstetrics and Gynaecology, Division of Obstetrics and Foetal Medicine of the Erasmus MC, University Medical Centre Rotterdam, The Netherlands. The study was designed to investigate parental health, environmental and genetic determinants in the pathogenesis and prevention of COD offspring. Data has been collected between 2003-2010 and the study design has previously been described in detail(14). The HAVEN study, enrolled 904 case and control mothers (Figure 1). Mothers pregnant at the study moment $(n=77)$, missing folate or homocysteine status $(n=94)$ and missing TL assessment $(n=3)$ were excluded from the analysis. In total, 306 case mothers of a child with COD and 424 control mothers of a child without congenital malformations were selected and included for analysis. In summary, all cases were diagnosed with COD by ultrasound and/or cardiac catheterization and/or surgery by a paediatric cardiologist. Control children and their parents were eligible if congenital malformations or chromosomal abnormalities were not present. The VSD group consist of perimembranous ventricular septal defects and atrioventricular septal defects. Only singletons, biological parents with no familial relationship and whom are familiar with the Dutch language (writing and reading), could participate. Venous blood samples were drawn from all mothers, approximately 1 year after the periconception period of the index-pregnancy, i.e., around 15 months. The same interval was used to obtain general information lifestyle behaviours and demographic data by questionnaires. This interval was chosen to mimic the periconceptional health status of the mother and to minimize the risk of undiagnosed less severe COD in the control group. The study protocol was approved by The Central Committee on Research involving Human Subjects and the institutional review boards of all participating hospitals. All parents gave their written informed consent, as well as on behalf of their participating child.

DNA-isolation and Telomere length measurement Genomic DNA from case and control mothers was extracted from EDTA blood samples with the Reliaprep kit (Promega, Leiden, Netherlands) on a Tecan Evo robot. DNA concentrations were measured with the Nanodrop (ThermoFisher, Waltham, United States of America) and normalized to $50 \mathrm{ng} / \mathrm{ul}$. Relative TL (TS ratio) was measured using a qPCR assay based on the method described by Cawthon(15) with minor modifications. For each sample the telomere and 36B4 assay were run in the same well position but in different 384 wells PCR plates. Each reaction contained $2 \mathrm{ng}$ DNA, $1 \mathrm{uM}$ of each of the telomere primers (tel1b-forward: GGTTTGTTTGGGTTTGGGTTTGGGTTTGGGTTTGGGTT, tel2b-reverse: GGCTTGCCTTACCCTTACCCTTACCCTTACCCTTACCCTT) or $250 \mathrm{nM}$ of the 34B4 primers (36B4u-forward: CAGCAAGTGGGAAGGTGTAATCC, 36B4d-reverse: CCCATTCTATCATCAACGGGTACAA) and 1x Quantifast SYBR green PCR Mastermix (Qiagen, Hilden, Germany). The reactions 
for both assays were performed in duplicate for each sample in a QuantStudio Flex 7 real time PCR machine (Applied Biosystems, Waltham, United States of America). The cycle threshold (Ct) values and PCR efficiencies were calculated per plate using the MINER algorithm.(16) Duplicate Ct values with a Coefficient of Variance $(\mathrm{CV})$ of more than $1 \%$ were repeated a second time in a different run. The average $\mathrm{Ct}$ values (of the duplicate measurements) per sample were adjusted for PCR efficiency using the formula $\mathrm{Q}=1 /(1+\mathrm{PCR}$ eff) ${ }^{\wedge} \mathrm{Ct}$. The TS ratio was calculated by dividing the Q of the telomere assay by the Q of the 34B4 assay. Each 384 wells PCR plate contained a set of 7 control samples. The average TS ratio of these 7 samples was used to normalize for plate batch effects. To validate the measured TS ratios, 170 random samples were run twice and the $\mathrm{CV}$ of that experiment was $4.5 \%$.

\section{Statistical analyses}

Characteristics were compared between case and control mothers. Descriptive statistics of the study population were presented using means and standard deviations for normal distributed variables and median and interquartile range for skewed variables. Analysis was performed by Student $t$ test and Mann-Whitney $U$ test, respectively. Frequencies (proportions), were used for categorical variables and were compared by chi-square test. Spearman correlations was used to evaluate correlations between maternal age, and homocysteine, and TL. Multivariable logistic regression was used to compute crude and adjusted odds ratios (OR) per standard deviation (SD) decrease between the maternal $\mathrm{T} / \mathrm{S}$ ratio with $95 \%$ confidence intervals $(95 \%$ $\mathrm{CI}$ ) and COD and VSD risk in offspring. The ORs were adjusted for maternal age, as known confounder for TL and COD (model 1). In a second model, we additionally adjusted for maternal body-mass-index, ethnicity, education and use of alcohol or smoking during pregnancy based on the characteristics of the two study populations and literature. $(17,18)$ Since homocysteine is an important oxidative stress marker, the analyses were also performed after adjustment for homocysteine concentrations.

Probability values [?] 0.05 were considered statistically significant. All analyses were performed with R (R for Windows, version 3.5; R Core Team).

Funding The Bo Hjelt Foundation for Spina Bifida in memory of Madeleine Hjelt provided financial support for the conduct of the study and preparation of the manuscript. The funding source had no involvement in study design, data collection, analysis and interpretation of data, in the writing of the report nor in the decision to submit this article for publication.

\section{Results}

General characteristics, lifestyle, biomarkers as folate, homocysteine and vitamin concentrations and foetal outcomes, of case mothers and control mothers were summarized in Table 1 . The interval after index pregnancy, BMI, maternal COD incidence, ethnicity, use of alcohol, smoking and folic acid supplement use were comparable between both groups. Case mothers had a significantly higher age $(\mathrm{p}=0.009)$ with a mean age of 31,8 years in case mothers and 30,9 years in control mothers. A positive family history for COD was more common in case mothers. A significant difference was found in education level between cases and controls, where a low and high education level was more common in the case mothers. Homocysteine and folate concentrations were comparable between the groups. Birth weight of offspring was significantly lower in the group of case mothers compared to control mothers. Preterm birth was significantly more common in case mothers. The COD phenotypes of case children $(\mathrm{n}=306)$ comprised aortic valve stenosis $(\mathrm{n}=7)$, atrioventricular septal defect $(\mathrm{n}=29)$, perimembranous ventricular septal defect $(\mathrm{n}=84)$, pulmonary valve stenosis $(\mathrm{n}=42)$, coarctation of the aorta $(\mathrm{n}=33)$, hypoplastic left heart syndrome $(\mathrm{n}=12)$, transposition of the great arteries $(\mathrm{n}=50)$, tetralogy of Fallot $(\mathrm{n}=38)$ and others $(\mathrm{n}=11)$. Two hundred thirty four of the 306 cases were defined as isolated COD cases. Seventy three cases were non-isolated and had another major structural congenital anomaly besides COD. Forty two of the 72 non-isolated cases had a genetic syndrome, i.e. trisomy $(\mathrm{n}=27)$, deletion 22q11 $(\mathrm{n}=5)$, Noonan syndrome $(\mathrm{n}=4)$, Beckwith-Wiedemann syndrome $(\mathrm{n}=1)$, CHARGE syndrome $(\mathrm{n}=1)$, Saethre-Chotzen syndrome $(\mathrm{n}=1)$, Alagille syndrome $(\mathrm{n}=1)$, Kartagener syndrome $(n=1)$ and Turner syndrome $(n=1)$. The distribution of maternal TL (T/S ratio) among the controls, COD cases and VSD cases were depicted in Figure 2. Maternal age revealed a significantly 
inverse correlation with TL $(R=-0.13 ; \mathrm{p}=<0.001)$. There was no correlation between the homocysteine concentrations in plasma and TL $(R=0.037 ; \mathrm{p}=0.32)$ (Figure S1 ). A positive family history for COD was not significantly associated with TL. A multivariable logistic model was used to determine the independent association of maternal TL with COD risk in offspring (Table 2A ). Model 1 and model 2 showed no significant associations between shorter maternal TL, per decrease in standard deviation of TL, and the risk of COD offspring (crude OR 1.10 (95\%CI 0.95-1.27), $\mathrm{p}=0.22$ ). Model 1: adjOR 1.07 (95\%CI 0.92-1.24), $\mathrm{p}=0.37$ and Model 2: adjOR 1.07 (95\%CI 0.92-1.24), $\mathrm{p}=0,40$. The syndromal and non-syndromal COD group showed also a comparable non-significant association, crude OR 1.15 (95\% CI 0.84-1.58), $\mathrm{p}=0.36$ and crude OR 1.09 (95\%CI 0.93-1.27), $\mathrm{p}=0.28$, respectively. In addition, we analysed the association between TL and $\operatorname{VSD}(\mathrm{n}=113)$, and demonstrated that a shorter maternal TL is associated with a significantly increased risk of VSD in their offspring (crude OR 1.29 (95\% CI 1.04-1.61), $\mathrm{p}=0.02$, per standard deviation TL decrease). In Model 1 the association remained significant (adjOR 1.25 (95\% CI 1.01-1.55), p=0.04)(Table 2B ). In Model 2 the association slightly attenuated (adjOR 1.24 (95\% CI 1.00-1.55). After stratification, the syndromal VSD group showed no association between shorter maternal TL and the risk of VSD in offspring (crude OR 1.28 (95\% CI 0.88-1.89), $\mathrm{p}=0.20$ ). Whereas, the non-syndromal VSD group showed a significant association between shorter maternal TL and the risk of VSD in offspring (crude OR 1.29 (95\% CI 1.02-1.66), $\mathrm{p}=0.04$ ). In model 1 and model 2 this association remained, albeit not significant (adjOR 1.26 (95\% CI 0.99-1.62), $\mathrm{p}=0.06$ and adjOR 1.28 (95\% CI $1.00-1.64)$, respectively)(Table 2B ). Adjustment of the associations for homocysteine concentrations did not substantially affect the association between TL and the risk of COD and VSD offspring.

\section{Discussion}

\section{Main findings}

This is the first study showing that shortening of maternal TL per standard deviation decrease is associated with an almost 30\% increased risk of VSD in offspring that attenuated to $25 \%$ after adjustment for maternal age (adjOR 1.25 (95\% CI 1.01-1.55), $\mathrm{p}=0.04)$. Moreover, we demonstrated a significant association between shorter maternal TL and the non-syndromal VSD group (crude OR 1.29 (95\% CI 1.02-1.66), p=0.04), where after adjustment the association remained, but lost significance.

Strengths and limitations One of the main methodological strengths of this study is the use of the standardized samples taken approximately 1 year after the periconception period of the index pregnancy, which minimizes recall bias. Moreover, we prevented misclassification of cases and controls, given that most CODs are diagnosed during the first year of life. Another strength is the detailed description of the neural crestrelated COD phenotypes and the ethnic homogeneity of case and control families. Another strength is the stratification in syndromes. As COD as part of a syndrome is more likely to be due to chromosomal abnormalities. A limitation of our study could be the measurement of TL in blood, which may not be representative for TL in the maternal oocytes or embryonic cardiac cells. However, it has been shown that leukocyte TL is highly correlated with TL of other somatic tissues from the same individual such as muscle, fat, skin and synovial tissue. This indicates that a clear intra-individual synchronization in TL exists in adults,(19) suggesting blood cell TL to be a valid measurement. Mean TL is measured, while cell senescence seems to be related to the shortest TL per cell.(20) A limitation of our study is that there are more typical COD types such as arterial trunk and double outlet right ventricle. The representation of these group were low in our study population and we were most interested in the VSD group as this was our largestgroup ofthe HAVEN study and most common phenotype of COD.

\section{Interpretation}

Our data support our hypothesis of using TL as biomarker for multiple exposures of oxidative stress and inflammation to assess the risk of COD offspring in the future. However, maternal age is the strongest determinant in this association. Thereby, the intricacy of TL translates in a high inter-individual variability, when comparing same-aged people.(21). This may be an explanation for the non-significant association found between TL and the risk of COD in general. Therefore, in future studies larger sample sizes are needed. 
Previous studies in mice showed that, embryonic mice deficient in the telomerase gene show shorter TL and failure of closure of the neural tube as the main defect, suggesting that this developmental process is sensitive to telomere loss and chromosomal instability. $(13,22)$ These results support our findings, considering the similar risk factors neural tube defects and COD share. A hypothetical role of TL in neural tube defects (NTD) and COD is illustrated by the epidemiological and biological evidence of the association between hyperhomocysteinemia and increased risk of NTD and COD in offspring. $(6,13,23)$. Hyperhomocysteinemia is a sensitive biomarker of oxidative stress and as such may reduce the synthesis or increase the damage of DNA, including the telomeres. The underlying mechanism could be impairment of the programming due to global or gene specific hypomethylation of telomerase. (24) In our study homocysteine was comparable between the groups, however homocysteine levels tended to be higher in cases. In our study population no correlation between homocysteine and TL was found. Thereby, adjusting for homocysteine concentrations had no significant influence on the association between TL and the risk of COD and or VSD offspring. Entringer et all. proposed that the effect of suboptimal intrauterine conditions on initial setting of TL and telomerase activity, is mediated by the programming actions of stress-related maternal-placental-foetal oxidative and metabolic pathways, in a way that accelerate cellular dysfunction, ageing and disease over the lifespan.(25) Embryogenesis in early pregnancy is sensitive to excessive oxidative stressors in the environment, resulting in structural and functional changes in cells, tissues and organ systems. Changes in TL of cells in the foetal heart may also play a role in normal cardiac development during embryogenesis and supports the association between TL and increased risk of VSD offspring.(26) The process of foetal programming of telomeres may reflect an effect shown across generations, that influences the health and well-being of not only individuals but also their offspring. Thereby, mother-offspring correlation in TL appears to be stronger than the father-offspring correlation, regardless of the gender of offspring. $(27,28)$ These finding emphasize the importance of efforts for early prediction and prevention.

Other associations between TL and obstetric outcomes have also been reported. Telomerase activity is decreased or absent in placentas of foetal growth restricted newborns.(29) In this way, foetal growth restriction is a common occurrence during COD pregnancies.(30)

\section{Future Implications}

Our findings entails a new focus in the future scientific approach ofthe prediction and prevention of neural crest cell related COD. For example, our results can form the basis for animal studies in which the pathophysiological mechanism for neural crest-related COD can be further explored.

Moreover, it contributes to the recognition of the importance of a life course approach in women's and offspring's health. We believe there could be a role for E-health intervention platforms, such as www.smarter pregnancy.co.uk(31), by improving maternal health conditions, such as an adequate intake of vegetables, fruits and folic acid supplements, stop smoking and alcohol consumption, that reduce excessive oxidative stress in women contemplating pregnancy using TL as a marker.

Further studies and replications of our study with larger populations and worldwide collaboration platforms are needed to confirm our findings and identify maternal TL as a sensitive predictive biomarker.

Conclusion Shortening of maternal TL, due to maternal conditions including age, is associated with an almost $30 \%$ increased risk of VSD in the offspring. No association was found between maternal TL and the risk of neural crest-related COD offspring in the total COD group. These findings need further confirmation in other studies and congenital malformations, and on the predictive value of maternal TL before implementation in clinical practice. For example, specify and sensitivity studies using ROC curves.

The demonstration of an underlying role for maternal TL shortening and the association with neural crestrelated COD in the offspring, in particular VSD, identifies maternal TL as a possible long term biological marker of the long term oxidative stress status of women in their periconception period. Consequently, after additional research, maternal TL may be used as a biological marker in periconceptional risk assessment.

\section{Acknowledgements}


The authors wish to thank Pascal. P. Arp from the Department of Internal Medicine, Erasmus MC, University Medical Centre Rotterdam, Rotterdam, the Netherlands, for executing the telomere length measurements.

Conflicts of interest : The author(s) report(s) no conflict of interest.

\section{Contribution to Authorship}

RS initiated the study and DA reviewed the review data and wrote the first version of the article. RW, AE, JM and RS contributed to the design of the paper, co-writing of the article, revisions and gave input at all stages of the study. SW contributed to statistical analyses and interpretation of results. All authors have approved the final version of the manuscript.

\section{References}

1. Liu Y, Chen S, Zuhlke L, Black GC, Choy MK, Li N, et al. Global birth prevalence of congenital heart defects 1970-2017: updated systematic review and meta-analysis of 260 studies. Int J Epidemiol. 2019;48(2):455-63.

2. Lawoko S, Soares JJ. Quality of life among parents of children with congenital heart disease, parents of children with other diseases and parents of healthy children. Qual Life Res. 2003;12(6):655-66.

3. Wlodarczyk BJ, Palacios AM, Chapa CJ, Zhu H, George TM, Finnell RH. Genetic basis of susceptibility to teratogen induced birth defects. Am J Med Genet C Semin Med Genet. 2011;157C(3):215-26.

4. Gittenberger-de Groot AC, Bartelings MM, Deruiter MC, Poelmann RE. Basics of cardiac development for the understanding of congenital heart malformations. Pediatr Res. 2005;57(2):169-76.

5. Keyte A, Hutson MR. The neural crest in cardiac congenital anomalies. Differentiation. 2012;84(1):25-40.

6. Steegers-Theunissen RP, Boers GH, Trijbels FJ, Eskes TK. Neural-tube defects and derangement of homocysteine metabolism. N Engl J Med. 1991;324(3):199-200.

7. Verkleij-Hagoort A, Bliek J, Sayed-Tabatabaei F, Ursem N, Steegers E, Steegers-Theunissen R. Hyperhomocysteinemia and MTHFR polymorphisms in association with orofacial clefts and congenital heart defects: a meta-analysis. Am J Med Genet A. 2007;143A(9):952-60.

8. Boot MJ, Steegers-Theunissen RP, Poelmann RE, van Iperen L, Gittenberger-de Groot AC. Cardiac outflow tract malformations in chick embryos exposed to homocysteine. Cardiovasc Res. 2004;64(2):365-73.

9. Jenkins KJ, Correa A, Feinstein JA, Botto L, Britt AE, Daniels SR, et al. Noninherited risk factors and congenital cardiovascular defects: current knowledge: a scientific statement from the American Heart Association Council on Cardiovascular Disease in the Young: endorsed by the American Academy of Pediatrics. Circulation. 2007;115(23):2995-3014.

10. Martens DS, Plusquin M, Gyselaers W, De Vivo I, Nawrot TS. Maternal pre-pregnancy body mass index and newborn telomere length. BMC Med. 2016;14(1):148.

11. Bijnens EM, Zeegers MP, Derom C, Martens DS, Gielen M, Hageman GJ, et al. Telomere tracking from birth to adulthood and residential traffic exposure. BMC Med. 2017;15(1):205.

12. Babizhayev MA, Savel'yeva EL, Moskvina SN, Yegorov YE. Telomere length is a biomarker of cumulative oxidative stress, biologic age, and an independent predictor of survival and therapeutic treatment requirement associated with smoking behavior. Am J Ther. 2011;18(6):e209-26.

13. Aoulad Fares D, Schalekamp-Timmermans S, Nawrot TS, Steegers-Theunissen RPM. Preconception telomere length as a novel maternal biomarker to assess the risk of spina bifida in the offspring. Birth Defects Res. 2020;112(9):645-51. 
14. Verkleij-Hagoort AC, Verlinde M, Ursem NT, Lindemans J, Helbing WA, Ottenkamp J, et al. Maternal hyperhomocysteinaemia is a risk factor for congenital heart disease. Bjog. 2006;113(12):1412-8.

15. Cawthon RM. Telomere length measurement by a novel monochrome multiplex quantitative PCR method. Nucleic Acids Res. 2009;37(3):e21.

16. Zhao S, Fernald RD. Comprehensive algorithm for quantitative real-time polymerase chain reaction. J Comput Biol. 2005;12(8):1047-64.

17. Martens D. Telomere biology in early life and its environmental determinants. Hasselt: University of Hasselt; 2018.

18. Valdes AM, Andrew T, Gardner JP, Kimura M, Oelsner E, Cherkas LF, et al. Obesity, cigarette smoking, and telomere length in women. Lancet. 2005;366(9486):662-4.

19. Daniali L, Benetos A, Susser E, Kark JD, Labat C, Kimura M, et al. Telomeres shorten at equivalent rates in somatic tissues of adults. Nat Commun. 2013;4:1597.

20. Fani L, Hilal S, Sedaghat S, Broer L, Licher S, Arp PP, et al. Telomere Length and the Risk of Alzheimer's Disease: The Rotterdam Study. J Alzheimers Dis. 2020;73(2):707-14.

21. Muezzinler A, Zaineddin AK, Brenner H. A systematic review of leukocyte telomere length and age in adults. Ageing Res Rev. 2013;12(2):509-19.

22. Herrera E, Samper E, Blasco MA. Telomere shortening in mTR-/- embryos is associated with failure to close the neural tube. Embo J. 1999;18(5):1172-81.

23. Groenen PM, Peer PG, Wevers RA, Swinkels DW, Franke B, Mariman EC, et al. Maternal myo-inositol, glucose, and zinc status is associated with the risk of offspring with spina bifida. Am J Obstet Gynecol. 2003;189(6):1713-9.

24. Steegers-Theunissen RP, Twigt J, Pestinger V, Sinclair KD. The periconceptional period, reproduction and long-term health of offspring: the importance of one-carbon metabolism. Hum Reprod Update. 2013;19(6):640-55.

25. Entringer S, de Punder K, Buss C, Wadhwa PD. The fetal programming of telomere biology hypothesis: an update. Philos Trans R Soc Lond B Biol Sci. 2018;373(1741).

26. Booth SA, Charchar FJ. Cardiac telomere length in heart development, function, and disease. Physiol Genomics. 2017;49(7):368-84.

27. Factor-Litvak P, Susser E, Kezios K, McKeague I, Kark JD, Hoffman M, et al. Leukocyte Telomere Length in Newborns: Implications for the Role of Telomeres in Human Disease. Pediatrics. 2016;137(4).

28. Broer L, Codd V, Nyholt DR, Deelen J, Mangino M, Willemsen G, et al. Meta-analysis of telomere length in 19,713 subjects reveals high heritability, stronger maternal inheritance and a paternal age effect. Eur J Hum Genet. 2013;21(10):1163-8.

29. Fragkiadaki P, Tsoukalas D, Fragkiadoulaki I, Psycharakis C, Nikitovic D, Spandidos DA, et al. Telomerase activity in pregnancy complications (Review). Mol Med Rep. 2016;14(1):16-21.

30. Ghanchi A, Derridj N, Bonnet D, Bertille N, Salomon LJ, Khoshnood B. Children Born with Congenital Heart Defects and Growth Restriction at Birth: A Systematic Review and Meta-Analysis. Int J Environ Res Public Health. 2020;17(9).

31. van Dijk MR, Oostingh EC, Koster MPH, Willemsen SP, Laven JSE, Steegers-Theunissen RPM. The use of the mHealth program Smarter Pregnancy in preconception care: rationale, study design and data collection of a randomized controlled trial. BMC Pregnancy and Childbirth. 2017;17(1):46.

Figure Headings 
Figure 1: Flowchart of inclusions and exclusions of the study population in the HAVEN study (Heart Defects, Vascular Status, Genetic Factors and Nutrition). COD = congenital outflow defects.

Figure 2: Box-and-whisker plot demonstrating the distribution of telomere length (T/S ratio) in control mothers (offspring without congenital defects) $[\mathrm{N}=424]$ compared with A) total congenital outflow defect group (COD) $[\mathrm{N}=306]$ and $\mathrm{B}$ ) ventricular septal defect (VSD) group [N=113]. Boxplots present median, 10th, 25th, 75th, and 90th percentile. Telomere length were compared by Mann-Whitney U test.

Supporting Information Files: Figure S1: Correlations between maternal telomere length (T/S ratio) and a) maternal age and b) maternal plasma total homocysteine. Spearman rank correlation test is performed to test the correlations.

\section{Table Headings}

Table1. General characteristics of the study population of case mothers (COD offspring) and control mothers (offspring without congenital defects).

Legend Table 1.COD $=$ congenital outflow defects. $*$ presented as mean (SD). Data are presented as median $[\mathrm{IQR}]$ or number of individuals (proportions).

Table 2. Maternal telomere length (T/S ratio) in association with the risk of congenital outflow defects (COD) (A) or ventricular septal defect (VSD) (B) in offspring.

Legend Table 2.OR, odds ratio; CI, confidence interval of COD or VSD risk per standard deviation (SD) decrease in maternal $\mathrm{T} / \mathrm{S}$ ratio. OR for decrease in risk per $\mathrm{SD}$ showed as 1/OR, one $\mathrm{SD}$ maternal $\mathrm{T} / \mathrm{S}$ ratio $=0.163$. Telomere length $\left(\mathrm{T} / \mathrm{S}\right.$ ratio) measured at approximately 16 months after the index pregnancy. ${ }^{1}$ Risk estimates adjusted for maternal age ${ }^{2}$ Risk estimates adjusted for maternal age, maternal body-mass-index, ethnicity, education and use of alcohol or smoking during pregnancy.

Table1. General characteristics of the study population of case mothers (COD offspring) and control mothers (offspring without congenital defects).

\begin{tabular}{|c|c|c|c|c|}
\hline & $\begin{array}{l}\text { Case mothers } \mathrm{n}= \\
306\end{array}$ & $\begin{array}{l}\text { Control mothers } \mathrm{n} \\
=424\end{array}$ & Missings & $P$-value \\
\hline \multicolumn{5}{|l|}{ Demographics } \\
\hline $\begin{array}{l}\text { Maternal age, } \\
\text { years* }\end{array}$ & $31.8(4.7)$ & $30.9(4.6)$ & 1 & 0.009 \\
\hline $\begin{array}{l}\text { Time after } \\
\text { index-pregnancy, } \\
\text { months }\end{array}$ & $16.2[15.2,17.9]$ & $16.3[15.3,18.0]$ & 1 & 0.79 \\
\hline $\begin{array}{l}\text { Mode of } \\
\text { conception, } \\
\text { spontaneous }\end{array}$ & $289(94.4)$ & $401(94.6)$ & 1 & 0.82 \\
\hline $\begin{array}{l}\text { Body mass index, } \\
{[\mathrm{kg} / \mathrm{m} 2]}\end{array}$ & $24.0[22.0,28.0]$ & $24.0[22.0,27.0]$ & 1 & 0.25 \\
\hline Education level Low & $86(28.1) 126(41.2)$ & $93(22.1) 216(51.3)$ & 3 & 0.02 \\
\hline Intermediate High & $94(30.7)$ & $112(26.6)$ & & \\
\hline $\begin{array}{l}\text { Geographic origin } \\
\text { Western }\end{array}$ & $270(88.2) 36(11.8)$ & $356(84.2) 67(15.8)$ & 1 & 0.15 \\
\hline $\begin{array}{l}\text { Non-Western } \\
\text { Mother with } \\
\text { COD }\end{array}$ & $8(2.6)$ & $4(0.9)$ & 0 & 0.15 \\
\hline $\begin{array}{l}\text { Family history of } \\
\text { COD } \\
\text { Lifestyle }\end{array}$ & $43(14.1)$ & $31(7.3)$ & 0 & 0.009 \\
\hline
\end{tabular}




\begin{tabular}{|c|c|c|c|c|}
\hline & $\begin{array}{l}\text { Case mothers } n= \\
306\end{array}$ & $\begin{array}{l}\text { Control mothers } \mathrm{n} \\
=424\end{array}$ & Missings & $P$-value \\
\hline \multicolumn{5}{|l|}{$\begin{array}{l}\text { Periconception } \\
\text { use of }(\mathrm{n}(\%))\end{array}$} \\
\hline Alcohol & $113(36.9)$ & $138(32.5)$ & 4 & 0.51 \\
\hline Cigarettes & $57(18.6)$ & $87(20.5)$ & 0 & 0.56 \\
\hline $\begin{array}{l}\text { Folic acid and/or } \\
\text { (multi)vitamins }\end{array}$ & $254(83.0)$ & $339(80.1)$ & 0 & 0.38 \\
\hline \multicolumn{5}{|l|}{$\begin{array}{l}\text { Current use of (n } \\
(\%))\end{array}$} \\
\hline Alcohol & $157(51.3)$ & $233(55.0)$ & 1 & 0.47 \\
\hline Cigarettes & $53(17.3)$ & $78(18.4)$ & 2 & 0.57 \\
\hline $\begin{array}{l}\text { Folic acid and/or } \\
\text { (multi)vitamins }\end{array}$ & $83(27.1)$ & $107(25.3)$ & 0 & 0.64 \\
\hline \multicolumn{5}{|l|}{ Biomarkers } \\
\hline $\begin{array}{l}\text { Vitamine B12, } \\
\text { serum (pmol/L) }\end{array}$ & $\begin{array}{l}277.5[209.5 \\
361.8]\end{array}$ & $\begin{array}{l}260.0[201.0, \\
357.5]\end{array}$ & 0 & 0.36 \\
\hline $\begin{array}{l}\text { Plasma total } \\
\text { homocysteine, } \\
\text { plasma, (umol/L) }\end{array}$ & $10.1[8.4,12.5]$ & $9.7[8.2,11.8]$ & 0 & 0.05 \\
\hline $\begin{array}{l}\text { folate, serum } \\
(\mathrm{nmol} / \mathrm{L})\end{array}$ & $15.2[12.4,19.4]$ & $14.70[12.2,19.6]$ & 0 & 0.37 \\
\hline $\begin{array}{l}\text { folate, red blood } \\
\text { cell }(\mathrm{nmol} / \mathrm{L})\end{array}$ & $659[529,802]$ & $634[521,769]$ & 0 & 0.36 \\
\hline Birth outcomes & & & & \\
\hline $\begin{array}{l}\text { Foetal gender, } \\
\text { boys }\end{array}$ & $173(56.5)$ & $234(55.2)$ & 0 & 0.78 \\
\hline Birthweight & $\begin{array}{l}3,290[2,850, \\
3,650]\end{array}$ & $\begin{array}{l}3,500[3,200, \\
3,890]\end{array}$ & 1 & $<0.001$ \\
\hline $\begin{array}{l}\text { Preterm birth }(< \\
37 \text { weeks } \\
\text { gestation })\end{array}$ & $48(15.8)$ & $24(5.7)$ & 4 & $<0.001$ \\
\hline
\end{tabular}

LegendCOD $=$ congenital outflow defects. ${ }^{*}$ presented as mean (SD). Data are presented as median [IQR] or number of individuals (proportions).

Table 2. Maternal telomere length ( $\mathrm{T} / \mathrm{S}$ ratio) in association with the risk of congenital outflow defects (COD) (A) or ventricular septal defect (VSD) (B) in offspring.

\begin{tabular}{|c|c|c|c|c|c|c|c|}
\hline $\begin{array}{l}\text { A. Risk of } \\
\text { COD }\end{array}$ & $\begin{array}{l}\text { Cases } / \mathrm{c} \\
(\mathrm{n}=306\end{array}$ & $\begin{array}{c}\text { lErude OR } \\
(95 \% \text { CI })\end{array}$ & p-value & $\begin{array}{l}\text { OR }(95 \% \\
\text { CI })^{1}\end{array}$ & p-value & $\begin{array}{l}\text { OR }(95 \% \\
\text { CI })^{2}\end{array}$ & $\mathrm{p}$-value \\
\hline $\begin{array}{l}\text { Total } \\
\text { study } \\
\text { group }\end{array}$ & $306 / 424$ & $\begin{array}{l}1.10 \\
(0.95-1.27)\end{array}$ & 0.22 & $\begin{array}{l}1.07 \\
(0.92-1.24)\end{array}$ & 0.37 & $\begin{array}{l}1.07 \\
(0.92-1.24)\end{array}$ & 0.40 \\
\hline Syndromal & $45 / 424$ & $\begin{array}{l}1.15 \\
(0.84-1.58)\end{array}$ & 0.39 & $\begin{array}{l}1.07 \\
(0.79-1.48)\end{array}$ & 0.65 & $\begin{array}{l}1.04 \\
(0.75-1.44)\end{array}$ & 0.82 \\
\hline $\begin{array}{l}\text { Non } \\
\text { Syndromal }\end{array}$ & $261 / 424$ & $\begin{array}{l}1.09( \\
(0.93-1.27)\end{array}$ & 0.28 & $\begin{array}{l}1.07 \\
(0.92-1.25)\end{array}$ & 0.39 & $\begin{array}{l}1.07 \\
(0.92-1.26)\end{array}$ & 0.38 \\
\hline $\begin{array}{l}\text { B. Risk of } \\
\text { VSD }\end{array}$ & $\begin{array}{l}\text { Cases } / c \\
(n=113\end{array}$ & $\begin{array}{c}\text { blErude OR } \\
(95 \% \text { CI })\end{array}$ & p-value & $\begin{array}{l}\text { OR }(95 \% \\
\text { CI })^{1}\end{array}$ & p-value & $\begin{array}{l}\text { OR }(95 \% \\
\text { CI })^{2}\end{array}$ & $\mathrm{p}$-value \\
\hline
\end{tabular}




\begin{tabular}{|c|c|c|c|c|c|c|c|}
\hline $\begin{array}{l}\text { A. Risk of } \\
\text { COD }\end{array}$ & $\begin{array}{l}\text { Cases/contro } \\
(\mathrm{n}=306 / 424)\end{array}$ & $\begin{array}{c}\text { lErude OR } \\
(95 \% \mathrm{CI})\end{array}$ & p-value & $\begin{array}{l}\text { OR }(95 \% \\
\text { CI })^{1}\end{array}$ & $\mathrm{p}$-value & $\begin{array}{l}\text { OR }(95 \% \\
\text { CI })^{2}\end{array}$ & $\mathrm{p}$-value \\
\hline $\begin{array}{l}\text { Total } \\
\text { study } \\
\text { group }\end{array}$ & $113 / 424$ & $\begin{array}{l}1.29 \\
(1.04-1.61)\end{array}$ & 0.02 & $\begin{array}{l}1.25 \\
(1.01-1.55)\end{array}$ & 0.047 & $\begin{array}{l}1.24 \\
(1.00-1.55)\end{array}$ & 0.05 \\
\hline Syndromal & $30 / 424$ & $\begin{array}{l}1.28 \\
(0.88-1.89)\end{array}$ & 0.20 & $\begin{array}{l}1.19 \\
(0.82-1.76)\end{array}$ & 0.36 & $\begin{array}{l}1.13 \\
(0.77-1.69)\end{array}$ & 0.54 \\
\hline $\begin{array}{l}\text { Non } \\
\text { Syndromal }\end{array}$ & $83 / 424$ & $\begin{array}{l}1.29 \\
(1.02-1.66)\end{array}$ & 0.04 & $\begin{array}{l}1.26 \\
(0.99-1.62)\end{array}$ & 0.06 & $\begin{array}{l}1.28(1.00 \\
-1.64)\end{array}$ & 0.05 \\
\hline
\end{tabular}

LegendOR, odds ratio; CI, confidence interval of COD or VSD risk per standard deviation (SD) decrease in maternal $\mathrm{T} / \mathrm{S}$ ratio. OR for decrease in risk per $\mathrm{SD}$ showed as $1 / \mathrm{OR}$, one $\mathrm{SD}$ maternal $\mathrm{T} / \mathrm{S}$ ratio $=$ 0.163. Telomere length (T/S ratio) measured at approximately 16 months after the index pregnancy. ${ }^{1}$ Risk estimates adjusted for maternal age,${ }^{2}$ Risk estimates adjusted for maternal age, maternal body-mass-index, ethnicity, education and use of alcohol or smoking during pregnancy.

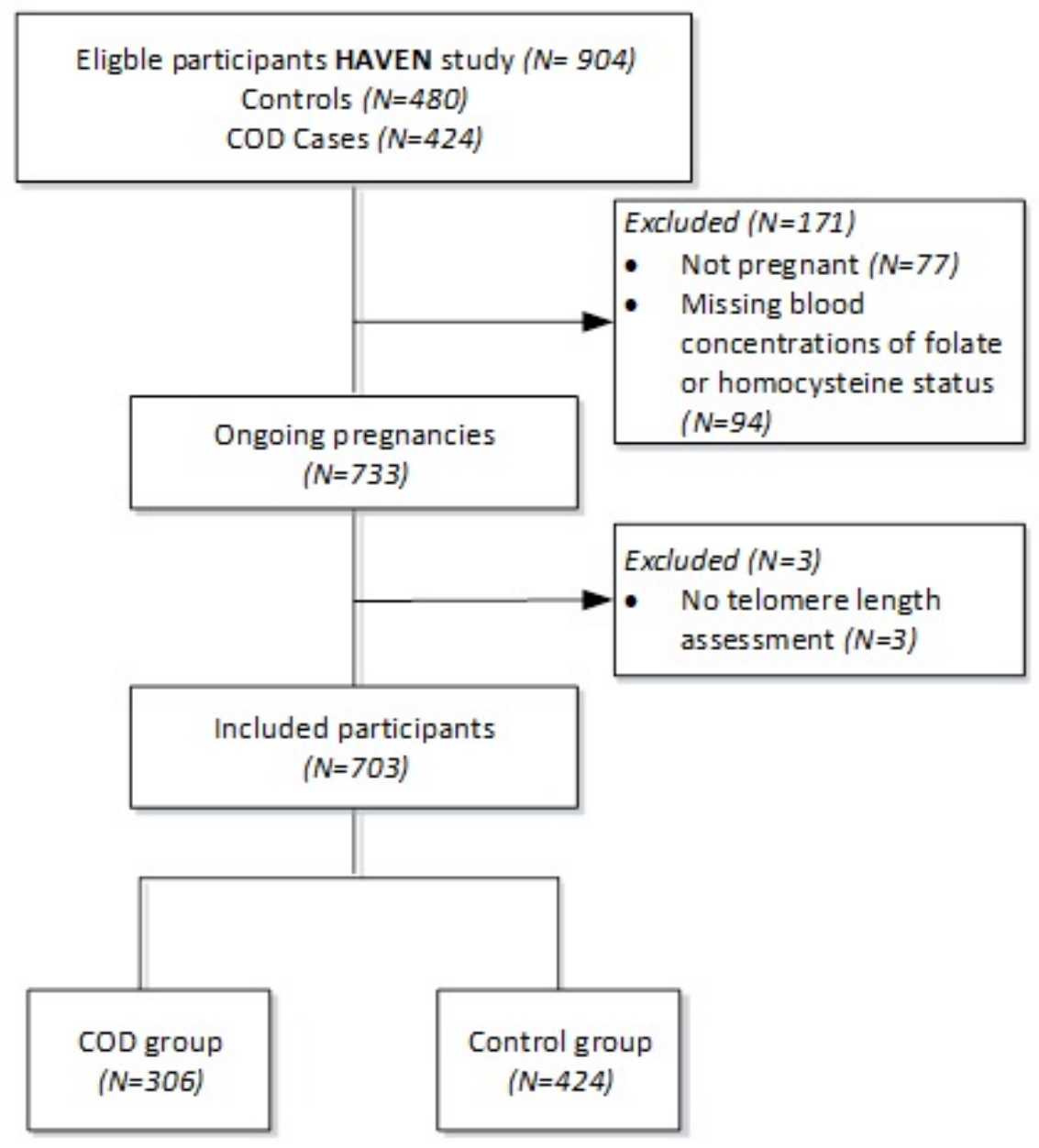



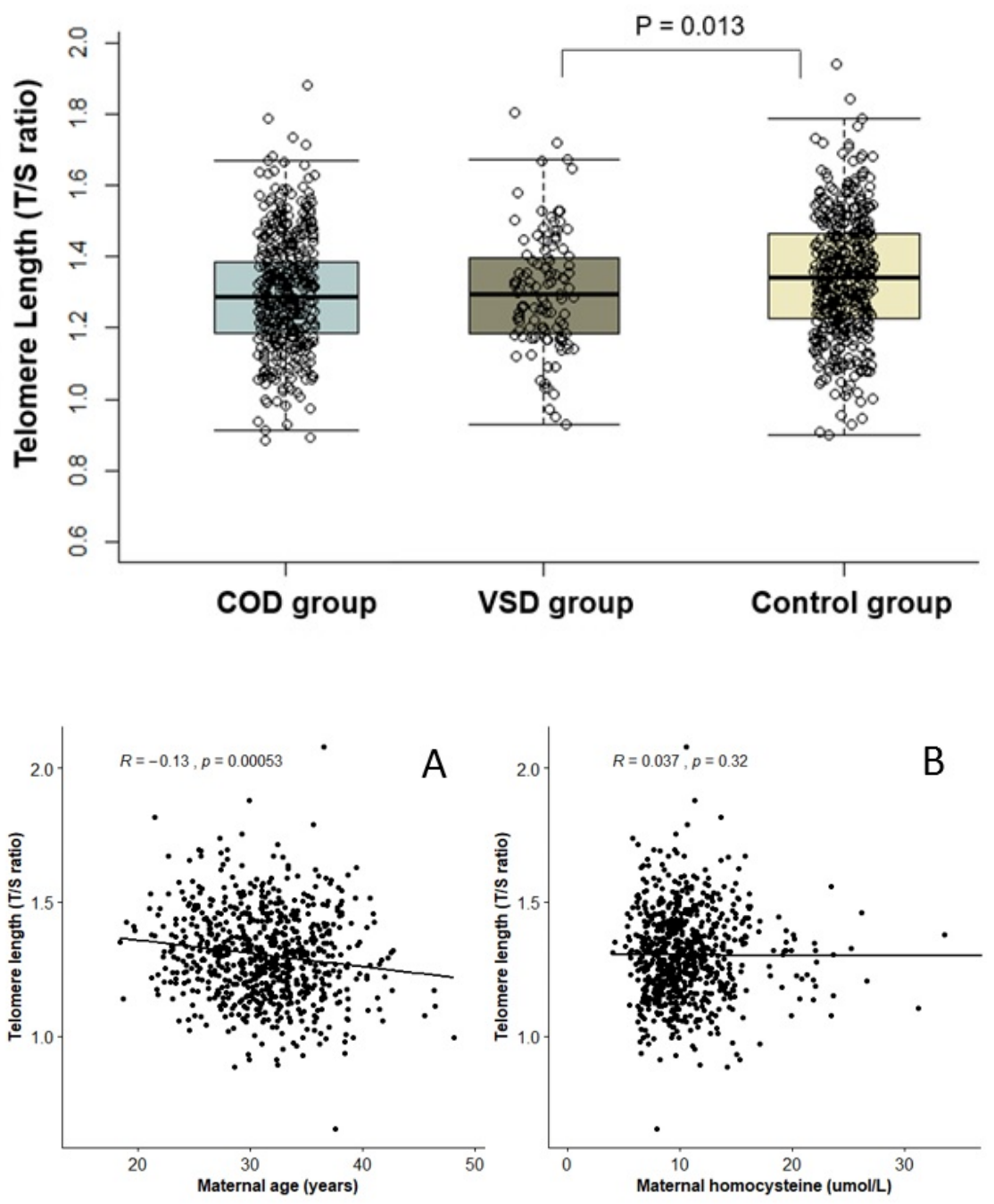